\title{
Application of Markov modelling and Monte Carlo simulation technique in failure probability estimation - A consideration of corrosion defects of internally corroded pipelines.
}

Chinedu I. Ossai*, Brian Boswell and Ian J. Davies

Department of Mechanical Engineering, Curtin University, GPO Box U1987, Perth, WA 6845, Australia

\begin{abstract}
For effective integrity management, the reliabilities at times of exposure of pipelines to corrosive environment need to be understood. This paper described the procedure for using Markov modelling and Monte Carlo simulation to determine the reliabilities of internally corroded pipelines. The corrosion wastage of the pipeline was classified with Pipeline Corrosivity Indexes (PCls), which were expressed as functions of retained pipe-wall thickness at exposure times. The model was tested on X52 grade pipeline that was monitored by Magnetic Flux Leakage (MFL) In-Line-Inspection (ILI) technique and the failure probabilities were determined for different failure scenarios such as small leakage, bursting and rupture. It was observed that, as the time of exposure of the pipeline to corrosive condition increased, there was a slight variation of the reliability of the pipeline that failed by bursting and rupture. The result also indicated a very high likelihood of small leakage of the pipeline than bursting and rupture. Since the failure probability of the corroded pipeline increases with increased time of exposure, it is expected that this model will be viability for the integrity management of internally corroded pipelines.
\end{abstract}

Keywords: Internally corroded pipeline; Reliability analysis; Markov modelling; Monte Carlo simulation; Pipeline corrosivity index

\subsection{Introduction}

Managing oil and gas pipelines entails the oversight of the corrosion problems, which degrade these assets over time in operation. Numerous research has pointed to corrosion as the major problem associated with pipelines used for oil and gas transportation [1-3], due to the enormity of downtime it contributes to the entire production process [4-5]. Hence, concerted efforts have been made by relevant stakeholders to predict the rate of corrosion and estimate the remaining useful life of corroded oil and gas pipelines. The work of researchers on the probabilistic estimate of pipeline corrosion using different techniques highlights the importance of this study area. Singh and Markeset [6] provided a hybrid approach for calculating the likelihood of failure of corroded pipelines under internal pressure by using a 2D fussy Monte Carlo simulation approach. Teixeira et al. [7] used the First Order Reliability Method (FORM) and Monte Carlo simulation in estimating the 
reliability of corroded pipeline subjected to corrosion while Qian et al. [8] depended on FITNET FFS procedure and Monte Carlo simulation for correlating the effects of corrosion defects on pipeline failure probability. Other researchers such as Pandey [9], utilized in-line inspection data obtained from a magnetic flux leakage technique for establishing the future time of pipeline inspection in consideration of the probability of failure of corroded pipeline whereas Ahmmed [10] adopted failure model that was based on fracture mechanics. Zhang et al. [11] utilized Monte Carlo simulation in the work, which focused on deterministic approach for corroded pipeline failure probability estimation. Keshtega and Miri [12] applied average shear stress criterion in their own probability estimation of corroded pipelines whereas Breton et al. [13] and Bisaggio and Netto [14] used Bayesian probability approach to estimate the probability risk of corroded pipelines.

Other researchers such as Paik and Kim [15] determined the effect of corrosion on the burst strength of a pipeline elbow by numerically analysing the effects of the internal and external pressure of the corroded elbow on its failure strength using finite element analysis. Other authors [16] used the scatter of corrosion wastage at exposure times to formulate an empirical model that was based on the Weibull function for estimating the future corrosion defect of steel structures exposure to salt water environment.

Although numerous research works have been carried out on pipeline corrosion estimation and probability analysis, there is limited information on failure probability estimation of corroded pipelines using Pipeline Corrosivity Index ( $\mathrm{PCI}$ ). Hence, this work aims to predict the failure probability and estimate the reliability of corroded pipelines in consideration of the retained pipewall thickness of corroded pipeline at a given time. The research will use Markov modelling and Monte Carlo simulation for predicting the survival probability of corroded pipelines at a given time for different corrosion wastage rates whilst using Weibull probability function to calculate the time lapse for pipeline leakage. Markov modelling and Monte Carlo simulation was used for the model developed in this paper because it has been used for estimating the failure probability of corrosion defect growth of corroded pipelines and other structures by numerous researchers [9-13]. Again, given the successful use of these techniques in different research areas for abstraction from reality, it is will be a useful tool for the prediction of future corrosion defect growth and reliability of pipeline corrosion in consideration of the internal operating pressure of the corroded pipeline. The failure probability of a corroded pipeline that is expected to fail by small leakage, burst and rupture will be determined for different corrosion wastage rates that will be measured with Poisson arrival rate. It is expected that the model developed in this research will be a viable tool for managing the integrity of corroded ageing pipelines. 


\subsection{Damage estimation model of corrosion wastage}

Corrosion defect depth of internal corroded pipeline can change with time of exposure of the pipeline to a corrosive environment. This time dependent phenomenon is most predominant between 8 O'clock and 4 O'clock zone of the pipeline because the flow of oil in the pipeline is concentrated in the region. By estimating the corrosion defect depth and length at different time intervals, the wastage rate of the corrosion defects of the pipeline can be determined for a given time according to Eq. (1). The corroded defect depth and length of a pipeline used for the damage estimation model is shown in Figure 1.

$C_{W}(t)=\left\{\begin{array}{l}\sum_{i=1}^{t} d_{i} \\ \sum_{i=1}^{t} L_{i} \\ i=1,2, \ldots, t\end{array}\right.$

Where $C_{W}(t), d$ and $L$ represents total corrosion wastage at time $t$, corrosion defect depth and corrosion defect length respectively.

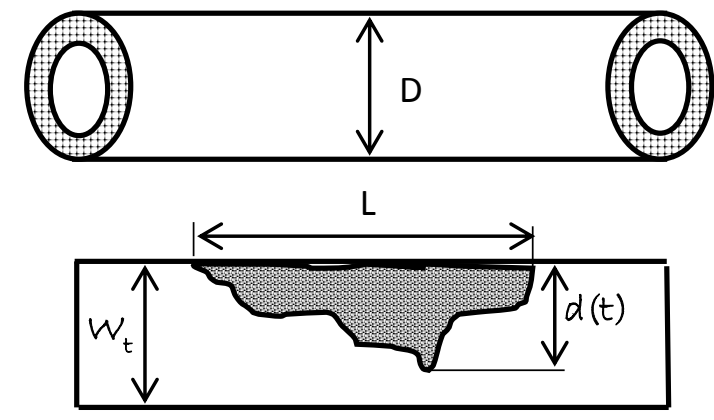

$\mathrm{d}(\mathrm{t})$ : cumulative corrosion defect depth at time t.

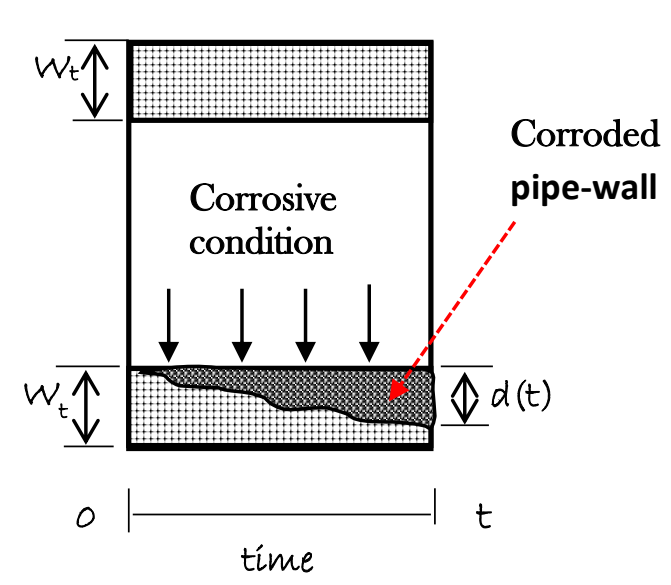

Figure 1: Corrosion wastage model for damage estimation

It is expected that the corrosion defect depth of the pipeline will increase cumulatively with the increase in the duration of exposure of the pipeline to the corrosive environment. This increase in the corrosion defect depth varies from year to year due to the random nature of corrosion depth growth that is necessitated by the variability in the operational condition of the pipeline [18], which influences the corrosive condition.

\subsection{Markovian modelling of corroded pipeline}

\subsection{Rating Corroded Pipelines}

Use of pipelines for transporting oil and gas results in their deterioration over time of usage due to the influence of the operating parameters such as, temperature, flow rate, $\mathrm{CO}_{2}$ and $\mathrm{H}_{2} \mathrm{~S}$ partial 
pressures, water cut, organic and inorganic salt content and sulphate reducing bacteria. This deterioration, which can be caused by erosion and corrosion generally results in the loss of the pipewall thickness. In order to minimize the risk of failure of this asset and plan for the integrity management, it is necessary that the wear of this pipeline is rated. Coincidentally, corrosion accounts for $50 \%$ to $75 \%$ of downtimes recorded in the oil and gas industry $[5,17]$ hence, the need for rating pipelines according to the Pipeline Corrosivity Index ( $\mathrm{PCI}$ ) as measured with pipe-wall thickness loss. Despite the fact that internal corrosion, stress corrosion cracking, pitting corrosion and uniform corrosion have gained prominence amongst researchers as can be seen in numerous literatures [2,14,18-19], it is important to note that to the best of our knowledge, limited information exist about calibrating pipeline failure risk with Pipeline Corrosivity Index (PCl) shown in Table 1.

Table 1: Pipeline Corrosivity Index (PCI) as a function of \% of the retained pipe-wall thickness

\begin{tabular}{lcl}
\hline $\begin{array}{l}\text { Pipeline Corrosivity Index } \\
(\mathrm{PCl})\end{array}$ & $\begin{array}{c}\text { Pipe-wall thickness } \\
\text { (Retained \%) }\end{array}$ & Remarks \\
\hline 1 & 5 & Zone of severe risk \\
2 & 10 & Acceptable level minimum deterioration \\
3 & 15 & \\
\hline 4 & 20 & \\
\hline 5 & 25 & \\
6 & 30 & \\
7 & 35 & \\
8 & 40 & \\
9 & 45 & \\
10 & 50 & \\
11 & 55 & \\
12 & 60 & \\
13 & 65 & \\
14 & 70 & \\
15 & 75 & \\
16 & 80 & \\
17 & 85 & \\
18 & 90 & \\
19 & 95 & \\
\hline 20 & 100 & \\
\hline & & \\
\hline & & \\
\hline & & \\
\hline
\end{tabular}

\subsection{Transition Probability and Pipeline Corrosivity Index (PCl) durations}

In order to estimate the transition probability, it was assumed that the pipeline corrosion wastage rate follows a discrete Weibull distribution and have a Poisson arrival rate that is independently 
exponentially distributed [20]. The statistical best fit, which was determined by considering the probability distribution functions shown in Table 2 and AKaike Information Criterion $\left(A_{I C}\right)$ shown in Equation (2), was used in a Monte Carlo simulation (see Figure 2). The shape and scale parameters of the discrete Weibull function was used for calculating the failure intensity, transition probabilities and $\mathrm{PCl}$ durations according to the expressions in Equations (3) - (5).

$\mathrm{A}_{\mathrm{IC}}=2 \mathrm{k}-2 \log (\mathrm{L})$

where $k$ and $L$ represents the number of parameters and the maximum value of the likelihood function respectively.

$\mathrm{D}_{\mathrm{PCI}}=\alpha_{\mathrm{ww}}\left(-\log \left(\mathrm{P}_{\mathrm{rtd}}\right)\right)^{\left(1 / \beta_{\mathrm{w}}\right)}$

$\eta=\frac{\beta_{\mathrm{w}}}{\alpha_{\mathrm{w}}}\left(\frac{\mathrm{D}_{\mathrm{pCI}}}{\alpha_{\mathrm{w}}}\right)^{\beta_{\mathrm{w}}-1}$

$\mathrm{T}_{\mathrm{P}}=\mathrm{e}^{-\eta * \mathrm{D} P C I}$

where $\alpha_{w}, B_{w}, P_{r t d}, D_{P C l}, T_{p}, \eta$ represents scale parameter for corrosion wastage, shape parameter for corrosion wastage, percentage of retained pipe-wall thickness at $\mathrm{PCl}, \mathrm{PCl}$ duration, transition probability and failure intensity. 


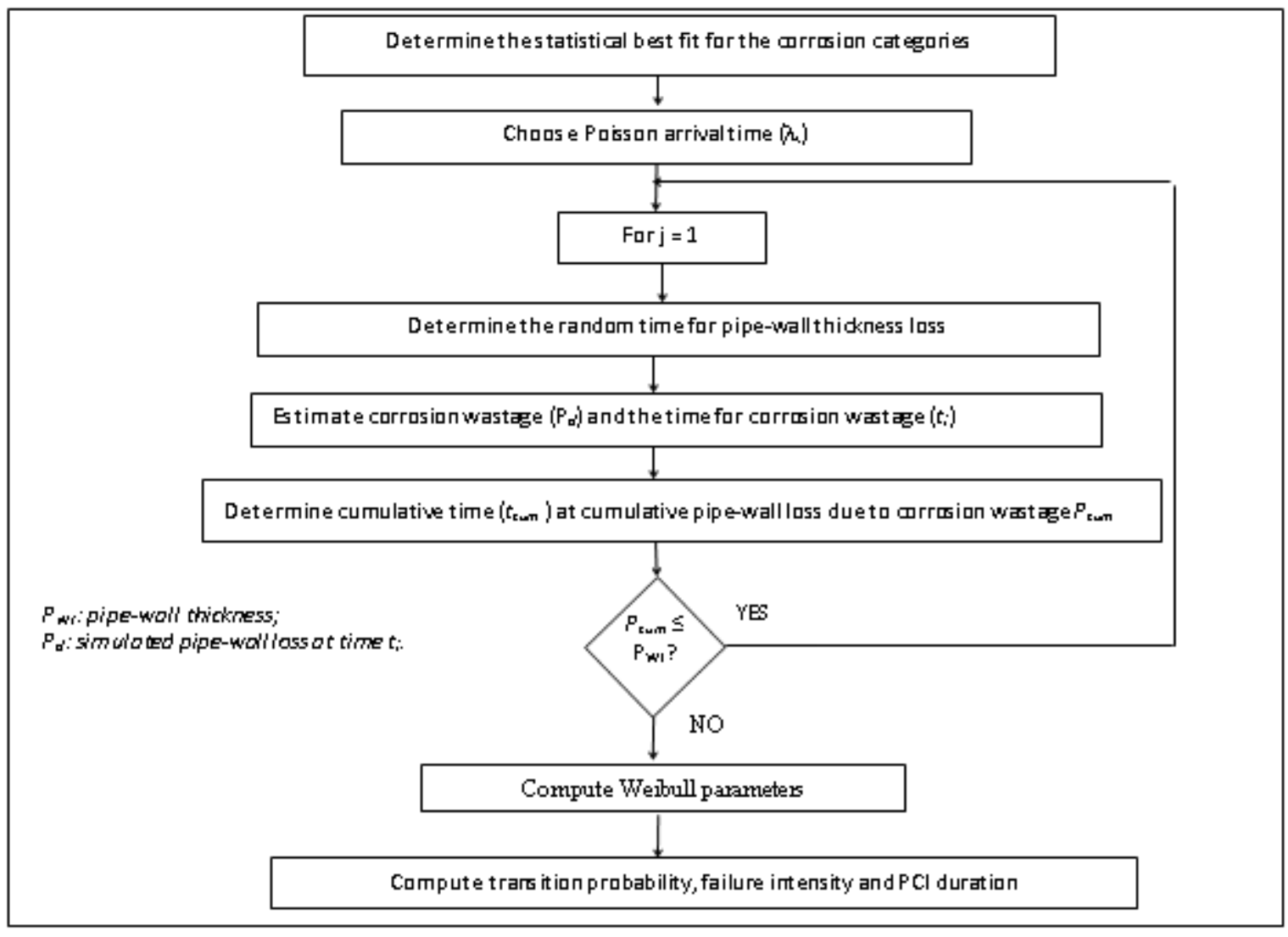

Figure 2: Monte Carlo simulation framework for estimation of time elapse for corrosion wastage. 
Table 2: Probability density distributions used to estimate the statistical best fit

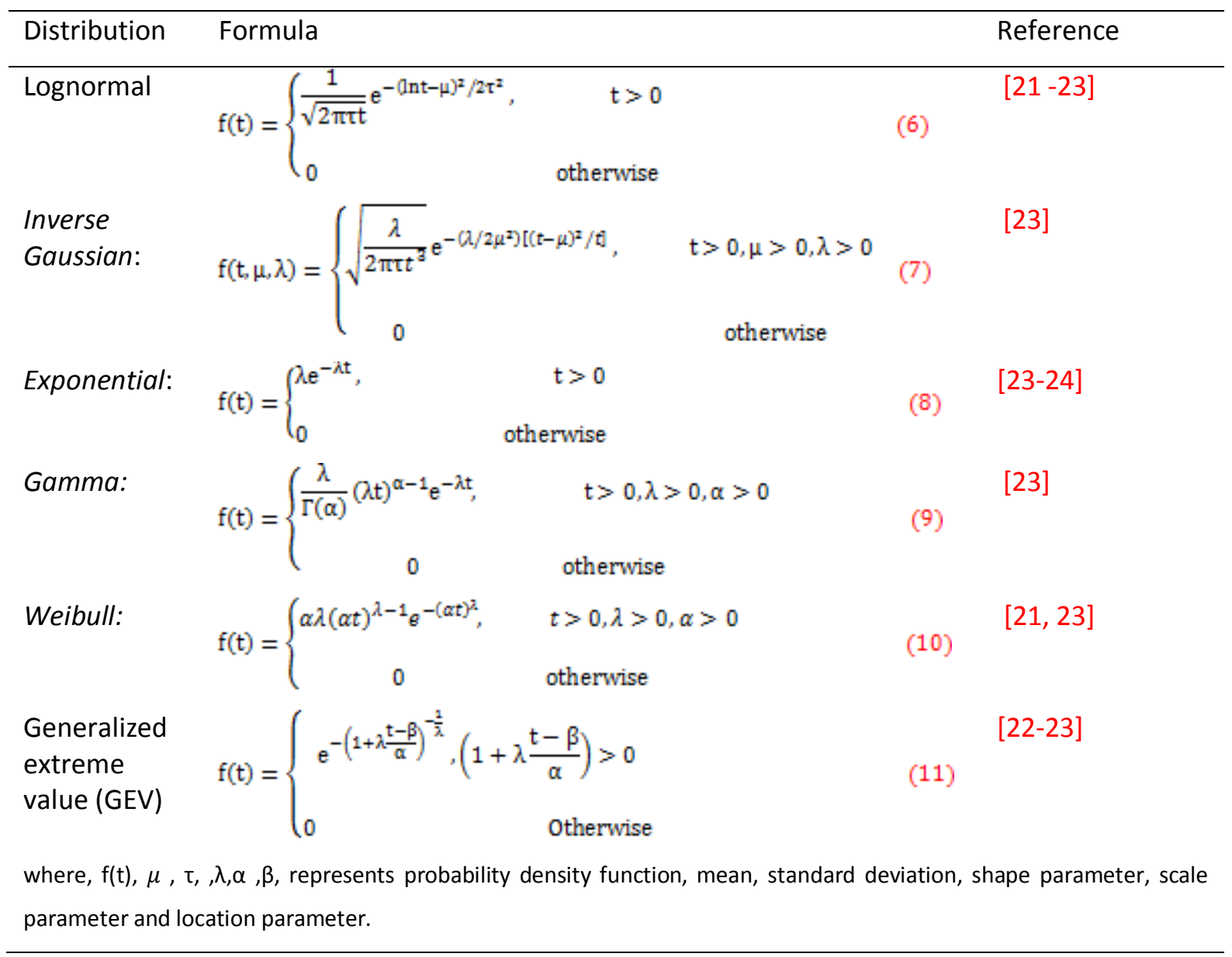

The Monte Carlo simulation approach utilized Poisson Square Wave Process (PSWP) [20], which used Poisson arrival rates $\left(\lambda_{t}\right)$ of $0.25,0.5$ and 0.75 for estimating corrosion wastage rates, $\mathrm{PCl}$ durations and lifecycle of the pipeline. It should be noted that the use of varying arrival rates will give an indication of the impacts of different degrees of corrosion wastage rates on the performance of corroding pipelines. The expected time of pipeline leakage $\left(t_{\text {leak }}\right)$ due to corrosion wastage at times $t_{1}, t_{2}, \ldots, t_{i}, t_{i+1}$ and the cumulative corrosion wastage $\left(P_{\text {cum }}\right)$ at the time of leakage can be expressed using Equations (12) - (14).

$$
\begin{aligned}
& t_{\text {leak }}=\sum_{i=1}^{n} t_{i} \\
& \mathrm{P}_{\mathrm{d}}\left(\mathrm{t}_{\mathrm{i}+1}\right)=\mathrm{P}_{\mathrm{d}}\left(\mathrm{t}_{\mathrm{i}}\right)+\mathrm{P}_{\mathrm{d}}\left(\mathrm{t}_{\mathrm{i}+1}-\mathrm{t}_{\mathrm{i}}\right), \mathrm{i}=1,2, \ldots, \mathrm{n} \\
& \mathrm{P}_{\text {cum }}=\mathrm{P}_{\mathrm{d}}\left(\mathrm{t}_{\mathrm{i}}\right)+\mathrm{P}_{\mathrm{d}}\left(\mathrm{t}_{\mathrm{i}+1}\right)+\mathrm{P}_{\mathrm{d}}\left(\mathrm{t}_{\mathrm{i}+2}\right)+. . \\
& =\sum_{i=1}^{n} P_{d_{i}}
\end{aligned}
$$


Where $\mathrm{n}$ represents the number of pulses that will result in the loss of the pipe-wall thickness and $P_{d_{i}}$ is the simulated corrosion wastage at $i^{\text {th }}$ pulse.

\subsection{Performance of Corroded Pipeline}

To determine the performance at the Pipeline Corrosivity index ( $\mathrm{PCl})$ of an $m$ state vector of an internally corroded pipeline having a transition matrix shown in Equation (15), it was assumed that the $\mathrm{PCl}$ will remain in one state or will not drop more than one state in approximately 2 years. This assumption was based on the fact that the design life of the pipeline is between 30 years to 40 years. At zero year, the initial state vector $P_{0}(1)$ is represented as: $\{1,0,0,0,0,0,0,0,0,0,0,0,0,0,0,0,0,0,0,0\}$.

$\mathrm{P}=\left[\begin{array}{ccccccc}\mathrm{P}_{1,1} & 1-\mathrm{P}_{1,1} & 0 & 0 & \ldots & 0 & 0 \\ 0 & \mathrm{P}_{2,2} & 1-\mathrm{P}_{2,2} & 0 & \ldots & 0 & 0 \\ 0 & 0 & \mathrm{P}_{3,3} & 1-\mathrm{P}_{3,3} & \ldots & 0 & 0 \\ \vdots & \vdots & \ddots & \vdots & \vdots & \vdots & \vdots \\ 0 & 0 & \ldots & 0 & \ldots & \mathrm{P}_{\mathrm{m}-1, \mathrm{~m}-1} & 1-\mathrm{P}_{\mathrm{m}-1, \mathrm{~m}-1} \\ 0 & 0 & \ldots & 0 & \ldots & 0 & 1\end{array}\right]$

The state vector at the $\mathrm{PCl}\left(P_{s t}\right)$ at a future time $(t)$ can be obtained by considering the transition probabilities from state $i$ to $j\left(P_{i, j}\right)$ using Equation (16). (NB: state $i$ to $j$ represents the transition from one $\mathrm{PCl}$ to another in the corrosion process).

$\mathrm{P}_{\mathrm{st}}(\mathrm{t})=\sum_{\mathrm{i}=1}^{2 \mathrm{n}_{\mathrm{s}}} \mathrm{P}_{0} \mathrm{P}^{\mathrm{i}}, \mathrm{t} \geq 2, \mathrm{n}_{\mathrm{s}}=\operatorname{int}\left(\frac{\mathrm{t}}{2}\right)$

If the vector of the $\mathrm{PCl}\left(V_{R}\right)$ and the transpose of the vector $\left(V_{R}{ }^{\prime}\right)$ shown in Equation (17) and (18) is manipulated, the $\mathrm{PCl}$ at a future time $t\left(P_{c l}\right)$ can be calculated with Equation (19).

$V_{R}=\{m, m-1, m-2, m-3, \ldots, 3,2,1,0\}$

$\mathrm{V}_{\mathrm{R}}=\left[\begin{array}{c}\mathrm{m} \\ \mathrm{m}-1 \\ \mathrm{~m}-2 \\ \mathrm{~m}-3 \\ \vdots \\ 3 \\ 2 \\ 1 \\ 0\end{array}\right]$

$P_{C I}(t)=\sum_{i=1}^{2 n_{s}}\left(P_{0} P^{i}\right) V_{R}$ 


\subsection{Risk Probability Estimation}

The survival probability of the pipelines at the $\mathrm{PCls}$ and the failure rate of the pipelines were modelled as a Weibull probability distribution function following the Maximum Likelihood Estimate (MLE) technique. The probability density function of a Weibull distribution was expressed using the MLE function for the failure times as shown in Equation (20) [21].

$L\left(t_{1}, \ldots, t_{n} ; \lambda, \alpha\right)=\prod_{i=1}^{n}\left(\frac{\lambda}{\alpha}\right)\left(\frac{t_{i}}{\alpha}\right)^{\lambda-1} e^{-\left(\frac{t_{i}}{n}\right)^{\lambda}}$

Simplifying Equation (20) by taking the logarithms and differentiating with respect to $\alpha$ and $\lambda$ whilst equating to zero will result in Equation (21) and (22).

$$
\begin{aligned}
& \frac{\sum_{i=1}^{n} t_{i}^{\lambda} \ln t_{i}}{\sum_{i=1}^{n} t_{i}^{\lambda}}-\frac{1}{\lambda}-\frac{1}{n} \sum_{i=1}^{n} \ln t_{i}=0 \\
& \alpha=\frac{\sum_{i=1}^{n} t_{i}^{\lambda}}{n}
\end{aligned}
$$

The survivability index over time $\left(S_{\text {Index }}(t)\right)$ at the PCls due to corrosion wastage can be expressed as shown in Equation (23).

$$
\mathrm{S}_{\text {Index }}(\mathrm{t})=\mathrm{P}(\mathrm{t}>0)=\mathrm{e}^{-\left(\frac{\mathrm{t}}{\mathrm{a}}\right)^{\mathrm{A}}}
$$

\subsection{Corroded pipeline reliability at the PCls}

The limit state function shown in Equation (24) [24-25] was used for describing the reliability of the corroded pipelines at the Pipeline Corrosivity Indexes (PCIs).

$$
\left\{\begin{array}{l}
g_{1}=0.8 w_{t}-d \\
g_{2}=r_{b}-P_{0} \\
g_{3}=r_{r p}-P_{0}
\end{array}\right.
$$

Where $w_{t}, d, r_{b}, r_{r p}, P_{0}$ represents pipe-wall thickness, corrosion defect depth, burst pressure, rupture pressure and operating pressure respectively. When $g_{1} \leq 0$, it is expected that the pipeline will have small leakage [25]. Although research has shown that pipelines may not leak when $80 \%$ of the pipe-wall thickness is lost as stipulated in Equation (24), however, it is should be noted that this standard, which is used in the oil and gas industry is aimed at ensuring low risk management of corroding pipelines [25-28].

For a bust failure to occur in a pipeline, it is expected that $\mathrm{g}_{2} \leq 0$ [25]. This sort of failure occurs due to plastic collapse and results in more flow than small leak. To calculate the burst pressure of a corroded pipeline requires the use of the standard burst pressure estimation models such as, ASME B31G, modified ASME B31G, RSTRENG, PCORRC, FITNET FFS, shell 92 and DNV RP-F101 [28-29]. For the purpose of this research, the pipeline burst failure was calculated with FITNET FFS model shown in Equation (25) [30]. 
$\mathrm{r}_{\mathrm{b}}=\frac{2 \sigma_{\mathrm{uts}} \mathrm{w}_{\mathrm{t}}\left(\frac{1}{2}\right)^{\left(65 / \sigma_{\mathrm{YS}}\right)}}{\mathrm{D}-\mathrm{w}_{\mathrm{t}}}\left[\frac{1-\frac{\mathrm{d}}{\mathrm{w}_{\mathrm{t}}}}{1-\frac{\mathrm{d}}{\mathrm{w}_{\mathrm{t}}} \mathrm{Q}^{-1}}\right]$

Where $D, \sigma_{u t s}, \sigma_{Y s}, L$ represents external diameter, ultimate tensile strength, yield stress and corrosion defect length of the pipeline respectively whereas $Q$, which is the length correction factor is shown in Equation (26).

$Q=\sqrt{1+0.8 \frac{\mathrm{L}}{\sqrt{\mathrm{Dw} \mathrm{t}_{\mathrm{t}}}}}$

For a through-wall failure to occur i.e. failure by rupture, $g_{3} \leq 0$ [25]. To calculate the rupture pressure, the model developed by Kiefner et al. [29] for pressurized pipe containing through wall flaw reported in references [25] and shown in Equation (27) was used.

$\mathrm{r}_{\mathrm{rp}}=\frac{2 \mathrm{w}_{\mathrm{t}} \sigma_{\mathrm{f}}}{\mathrm{MD}}$

where the folias factor $(M)$ is shown in Equation (28) and $\sigma_{f}$ represents the flow stress, which is $90 \%$ of the ultimate tensile strength $[25,28]$.

$\mathrm{M}= \begin{cases}\sqrt{1=0.6275 \frac{\mathrm{L}}{\sqrt{\mathrm{Dw}}}-0.003375 \frac{\mathrm{L}_{\mathrm{t}}^{2}}{\mathrm{Dw}_{\mathrm{t}}}}, & \frac{\mathrm{L}}{\sqrt{\mathrm{Dw}}} \leq 7.071 \\ 0.032 \frac{\mathrm{L}}{\sqrt{\mathrm{Dw}}}+3.293, & \frac{\mathrm{L}}{\sqrt{\mathrm{Dw}}}>7.071\end{cases}$

The failure state $\left(f_{s}\right)$ of a corroded pipeline can be summarized using the limit state function and intersection $(\cap)$ of $g_{1}, g_{2}$ and $g_{3}$ according to Equation (29) $[25,26,28]$.

$f_{g}=\left\{\begin{array}{lr}g_{1} \leq 0 \cap g_{2}>0, & \text { small leak } \\ g_{1}>0 \cap g_{2} \leq 0, & \text { burst } \\ g_{1}>0 \cap g_{2} \leq 0 \cap g_{3}>0, & \text { large leak } \\ g_{1}>0 \cap g_{2} \leq 0 \cap g_{3} \leq 0, & \text { rupture }\end{array}\right.$

\subsection{Estimation of Failure Probability of Corroded Pipeline}

Monte Carlo simulation [7, 28-30] has been utilized by some researchers to determine the failure probability of corroded pipelines based on the limit state function [25-26] whereas others have used First Order Reliability Method (FORM) [7]. In this research, the failure probability $\left(P_{f}\right)$ of the pipelines at the Pipeline Corrosivity Indexes (PCls) were expressed according to Equation $(30)[7,23]$.

$P_{f}=\int_{g(x)} f_{g} d x$

Where $g(x)$ represents the limit state variable at the failure states (Equation (24)). Since it is complex to determine the failure probability using integration of the physical variables, estimation procedure 
based on Monte Carlo simulation has been often utilized in research [21,26, 28-30]. After estimating the failure probability, the reliability index $(\beta)$ can be obtained by using the inverse of the standard normal cumulative distribution function $\left(\phi^{-1}\right)$ according to Equation (31) [7].

$\beta=-\Phi^{-1}\left(\mathrm{P}_{\mathrm{f}}\right)$

The framework used for the estimation of the failure probabilities at the Pipeline Corrosivity Indexes (PCls) for small leak, burst and rupture failures is shown in Figure 3. Poisson square wave process $[20,32]$ was utilized for determining the time lapse for small leakage, burst and rupture failures in Figure 3. The statistical best fit of the corrosion defect depths were used for predicting the pipe-wall loss with time lapse of the Poisson arrival rates for small leak. The time taken to loss a fraction of the pipe-wall thickness at a particular PCI (see Table 1) was calculated from the simulation whereas the cumulative time required to loss $80 \%$ of the pipe-wall thickness was presumed the time for the pipeline failure as initially stated. For burst and rupture failures, $10^{3}$ to $1.5 \times 10^{5}$ simulation runs were carried out for the Poisson arrival rates. The time duration in hours calculated at the simulation runs were compared with the $\mathrm{PCl}$ durations computed with Equation (3). The simulation runs whose calculated duration were equivalent to the durations calculated with Equation (3) were used to compute the failure probability at the PCls according to the computation formulas given in Figure 3 . 


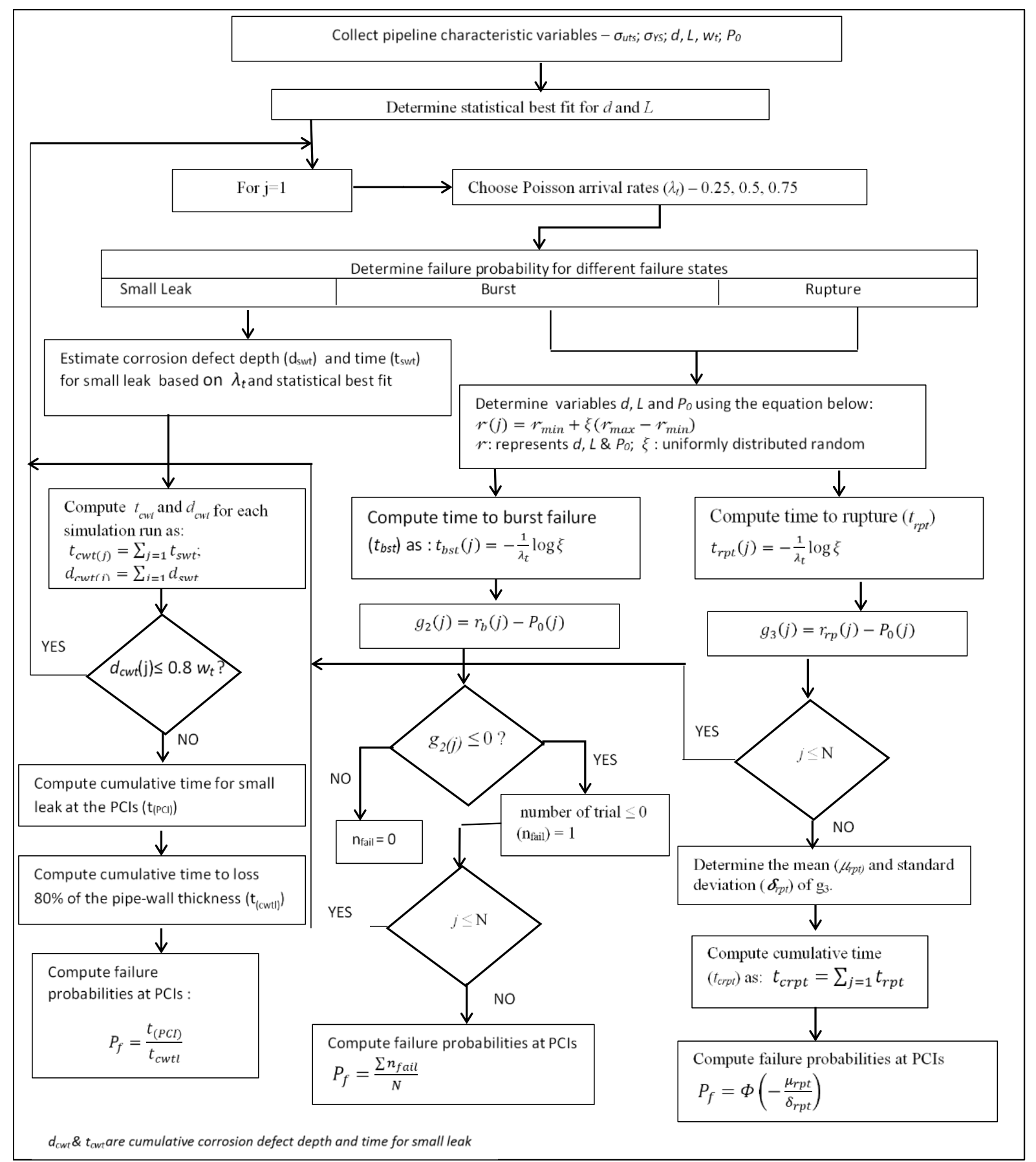

Figure 3: framework for estimating the failure probabilities at the Pipeline Corrosivity Indexes (PCIS)

\subsection{Application to oil and gas transmission pipelines 4.1 Distribution of corrosion defect lengths and depths}

To demonstrate the application of the proposed model in this research, Magnetic Flux Leakage (MFL) in-line inspection (ILI) data of X52 grade onshore transmission pipeline was used. This pipeline, which was inspected in 2011 was used for transporting heavy crude in the Niger Delta region of Nigeria. The corrosion wastage analysis and risk estimate of the first $5000 \mathrm{~m}$ of this 45,000 $\mathrm{m}$ pipeline was analysed in this work. The mean operating pressure of this $457.2 \mathrm{~mm}$ external diameter and $7.1 \mathrm{~mm}$ pipe-wall thickness pipeline is $3.0 \mathrm{MPa}$. This $5000 \mathrm{~m}$ analysed section of the 
pipeline has 7613 MFL ILI data points whose characteristic values of the corrosion defect depth and defect length is shown in Table 4.

Table 4: description of corrosion defect depth and length of the pipeline

\begin{tabular}{lll}
\hline Variables & Defect depth $(\mathrm{d})(\mathrm{mm})$ & defect Length $(\mathrm{L})(\mathrm{mm})$ \\
\hline Min & 0.07 & 1.00 \\
Max & 3.55 & 151.00 \\
Mean & 0.87 & 22.89 \\
Std. & 0.31 & 11.41 \\
skewness & 0.44 & 2.44 \\
Kurtosis & 1.57 & 11.14 \\
SE & 0.00 & 0.13 \\
COV & 0.35 & 0.50 \\
\hline
\end{tabular}

The statistical best fit distribution determined with Akaike Information Criterion (AIC) is shown in Table 5.

Table 5: Akaike Information Criterion (AIC) Values for corrosion defect Length (L) and depth (d) X52 pipeline

\begin{tabular}{lcc}
\hline Distribution & $\mathrm{L}(\mathrm{mm})$ & $\mathrm{d}(\mathrm{mm})$ \\
\hline Normal & 29335 & $\mathbf{2 7 9 0}$ \\
Exponential & 31446 & 6264 \\
Lognormal & 27520 & 5972 \\
Gamma & 27795 & 4007 \\
Weibull & 28581 & 3179 \\
GEV & $\mathbf{2 7 4 0 1}$ & 3045 \\
Inverse Gaussian & 27631 & 12617 \\
\hline
\end{tabular}

Since lower values of Akaike Information Criterion (AIC) are indications of better statistical fit [33], it can be deduced from Table 5 that generalized extreme value distribution (GEVD) with shape, scale and location parameters of $0.111,7.0975$ and 17.8781 respectively is the best fit statistics for defect length. Figure 4 shows the field data distribution of the corrosion defect length and the best fit statistical distribution. Table 5 also show that normal distribution with mean and standard deviation of 0.81847 and 0.35958 respectively is the best fitting distribution for the corrosion defect depth whose schematic is shown in Figure 5. 


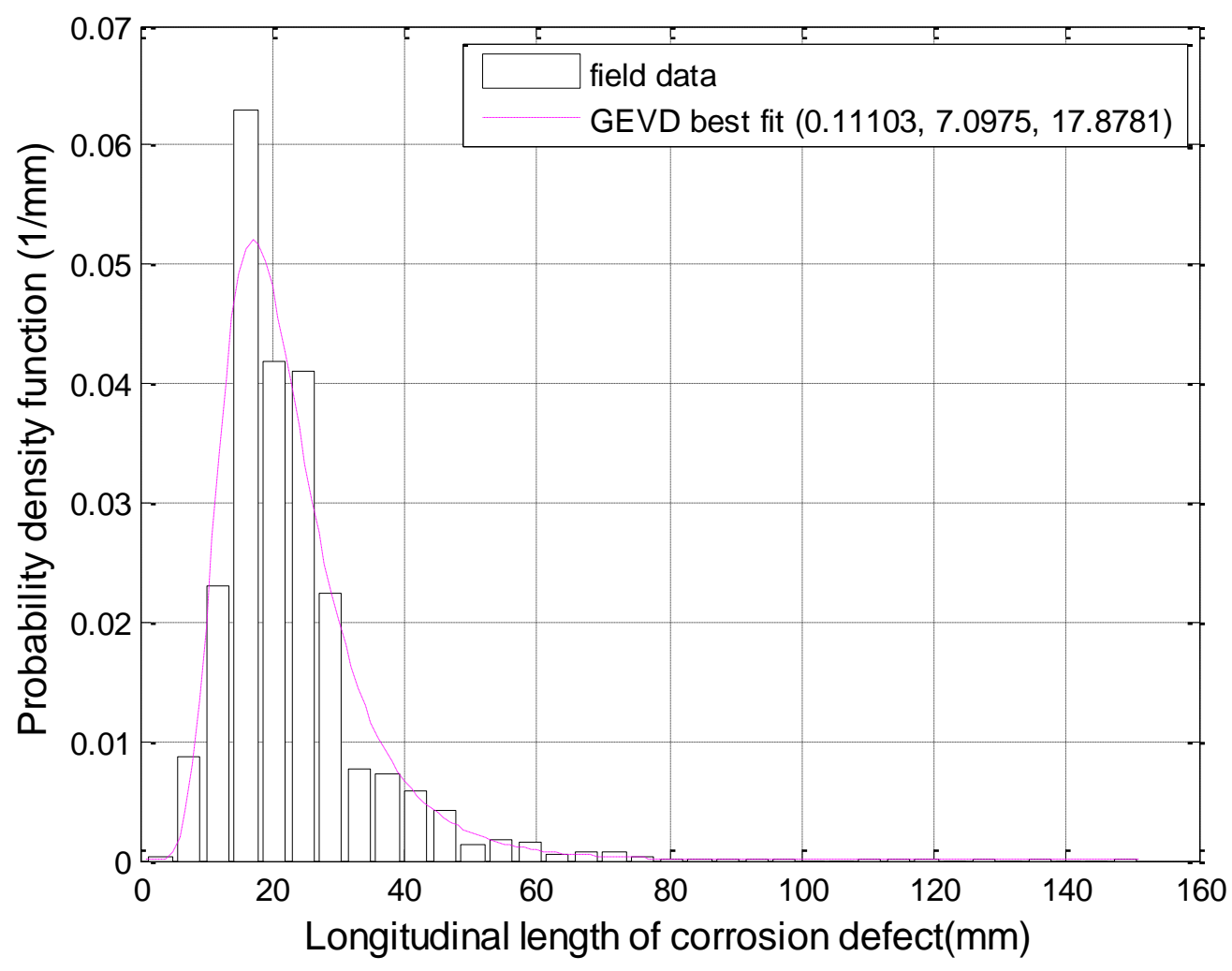

Figure 4: Probability density distribution of corrosion defect length and the statistical best fit

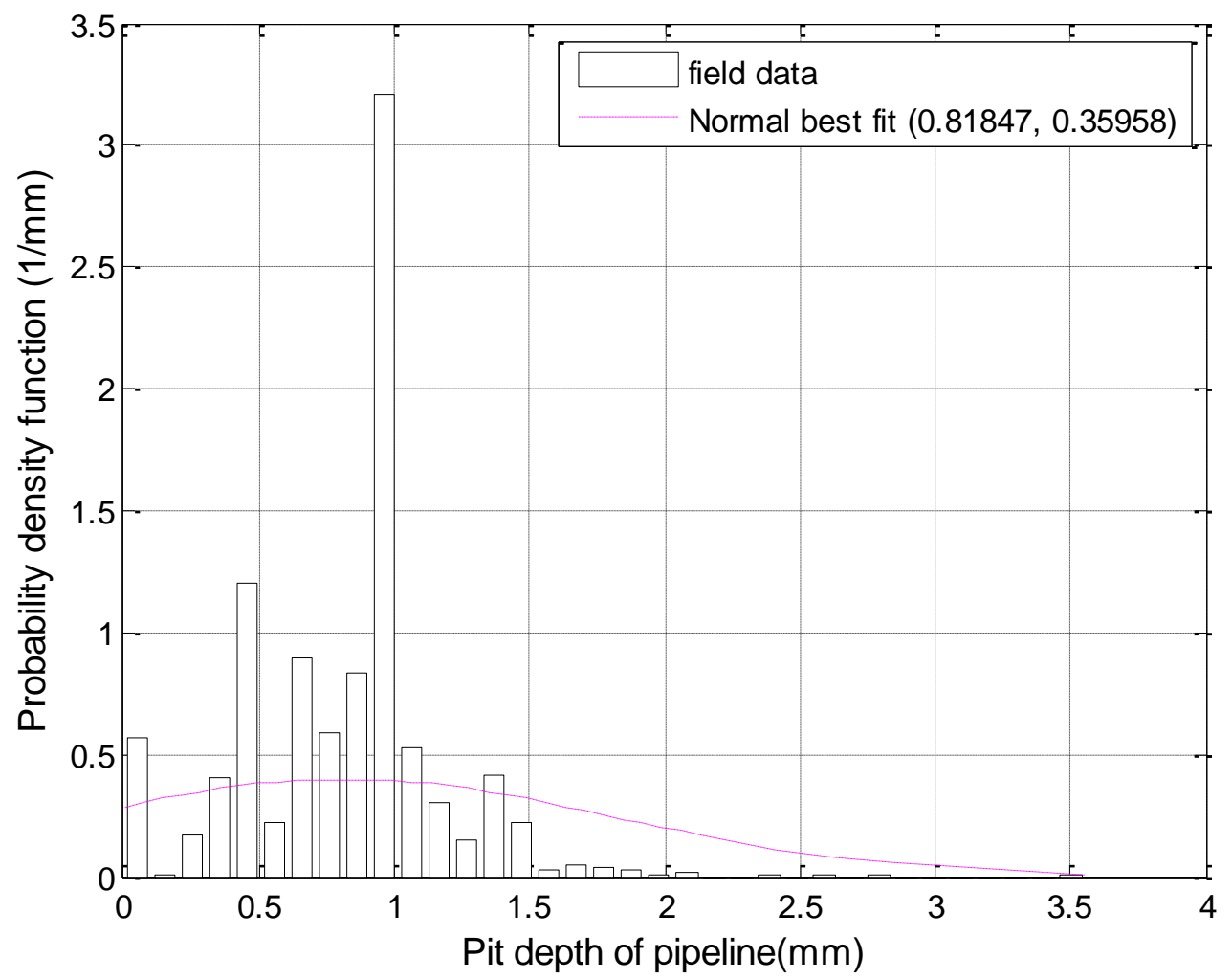

Figure 5: Probability density distribution of corrosion defect depth and the statistical best fit 


\subsection{Time dependent pipeline corrosion wastage}

Table 6 shows the Weibull parameters used for determining the time dependent corrosion wastage of the pipeline at the Pipeline Corrosivity Indexes (PCls) using different Poisson arrival rates whilst Figure 6 shows duration of pipeline exposure as a function of the PCls.

Table 6: Summary of Weibull parameters used for the simulation

\begin{tabular}{lll}
\hline Poisson arrival rate & Scale parameter & Shape parameter \\
\hline$\lambda=0.25$ & 26.0463 & 1.3231 \\
$\lambda=0.50$ & 15.8447 & 1.9948 \\
$\lambda=0.75$ & 6.2682 & 1.0391 \\
\hline
\end{tabular}

Table 6 indicates that the shorter the Poisson arrival rate, the higher the characteristic life of the pipeline and a resultant increased lifespan of the pipeline as shown in Figure 6. The effect of the Poisson arrival rates on the reliability and remaining useful life of the pipeline is synonymous to the impact of pitting corrosion categories on pipeline performance [30]. Hence, low Poisson arrival rate results in higher reliability of the pipeline than higher Poisson arrival as shown by the survivability index curve of Figure 7. For instance, when the survivability index of the curve in Figure 7 is approximately 0.5 , the lifespan of the pipeline was found to be approximately 20 years, 13 years and 6 years for Poisson arrival rates of $0.25,0.5$ and 0.75 respectively.

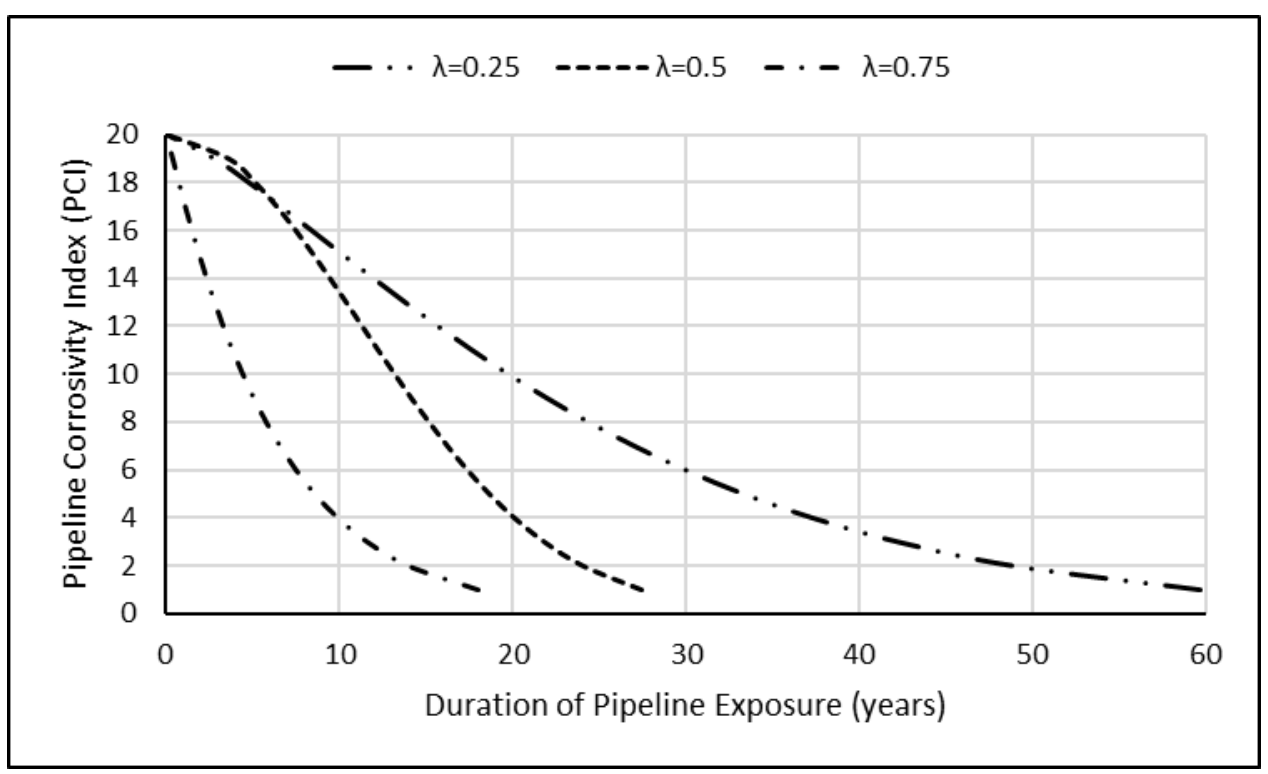

Figure 6: Time variation of the Pipeline Corrosivity Index (PCI) at different Poisson arrival rates 


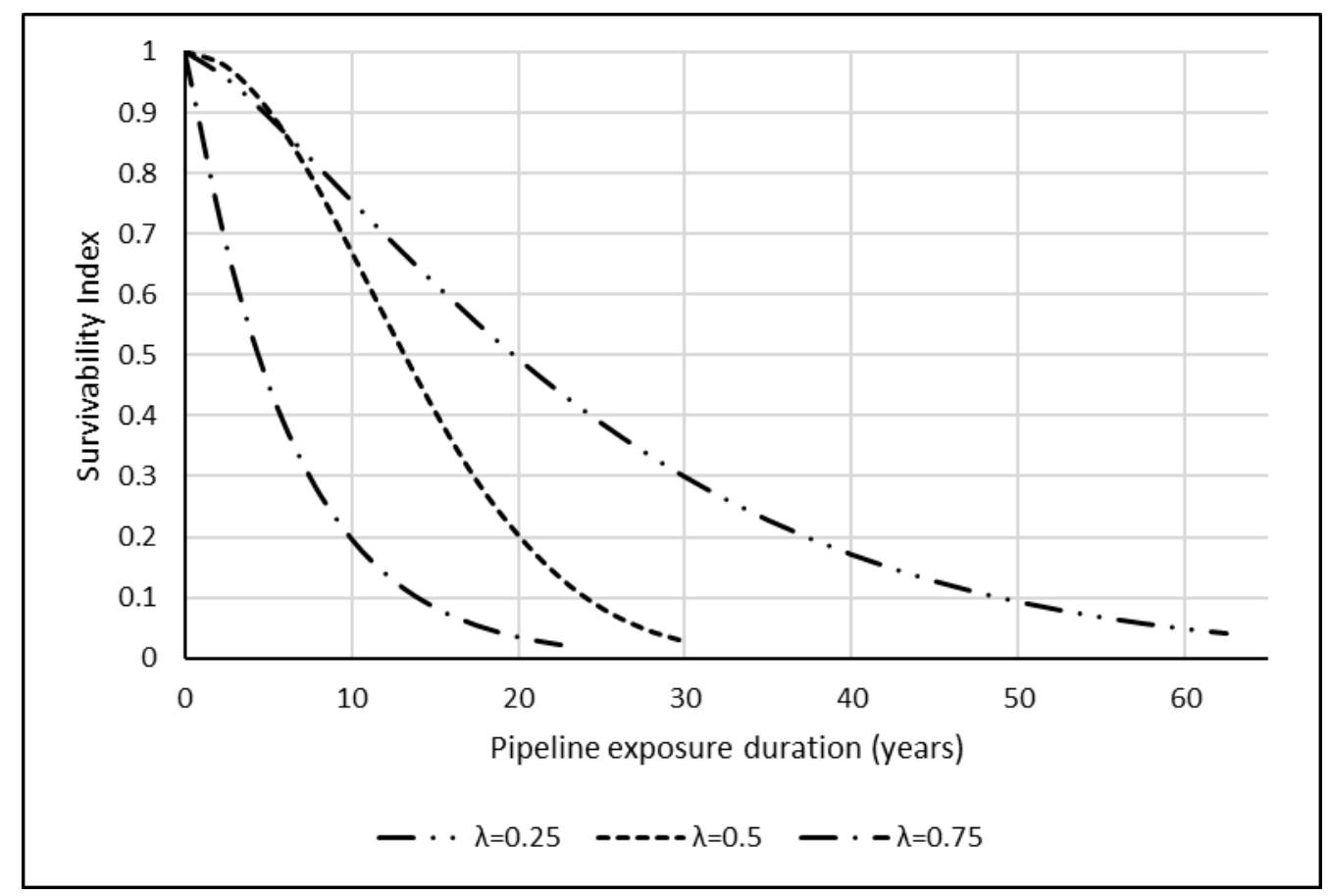

Figure 7: Survival probability curve of the pipeline estimated with different Poisson arrival rates

\subsection{Reliability analysis at Pipeline Corrosivity Index (PCI)}

In order to determine the reliability of the pipeline at the $\mathrm{PCls}$, the failure probability was determined for small leak, burst and rupture based on the framework shown in Figure 3. The mean operating pressure of the pipeline was assumed to vary at the rate of approximately $\mp 10 \%$ along the pipeline [34] whereas the value of the ultimate tensile strength and yield stress was adopted from [35].

For small leak, the failure probabilities across the PCls is shown in Figure 8. 


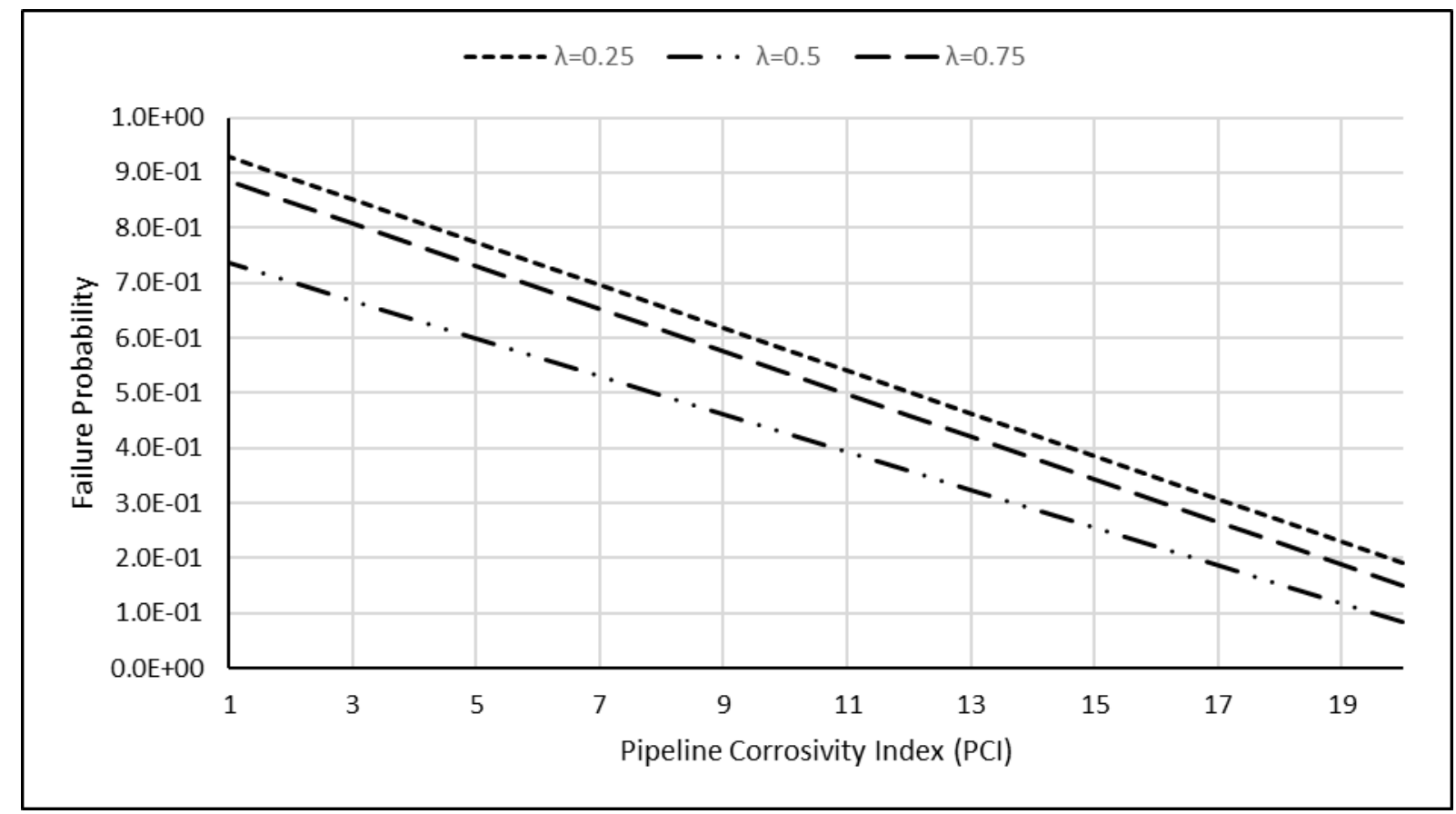

Figure 8: Variation of the failure probability of small leak for different Poisson arrival rates

It could be noted that, despite the fact that the failure probabilities are independent of the operating pressure of the pipeline, the values decreased as the $\mathrm{PCl}$ increased. Since lower $\mathrm{PCl}$ translates to more time of pipeline exposure (see Table 1 and Figure 6 ), it can be seen that the failure probability increases with time. This is in line with the expectation of ageing corroded pipelines as was shown by other researchers in this area [20,30,32]. The figure equally showed that lower Poisson arrival rate $\left(\lambda_{t}=0.25\right)$, which resulted in lower corrosion wastage has higher failure probabilities than other Poisson arrival rates. This is not abnormal seeing that the length of time of exposure of the pipeline at the $\mathrm{PCl}$ for different Poisson arrival rates are not the same.

The burst failure and rupture failure have been significantly impacted by operating pressures. The failure probability for burst and rupture related failures of this pipeline is shown in Figures 9 and 10 respectively. These figures also indicated that the failure probabilities increased with the increase of the duration of pipeline exposure to corrosion, however, the risk of failure by rupture at the Poisson arrival rates are generally lower than that of burst failures. 


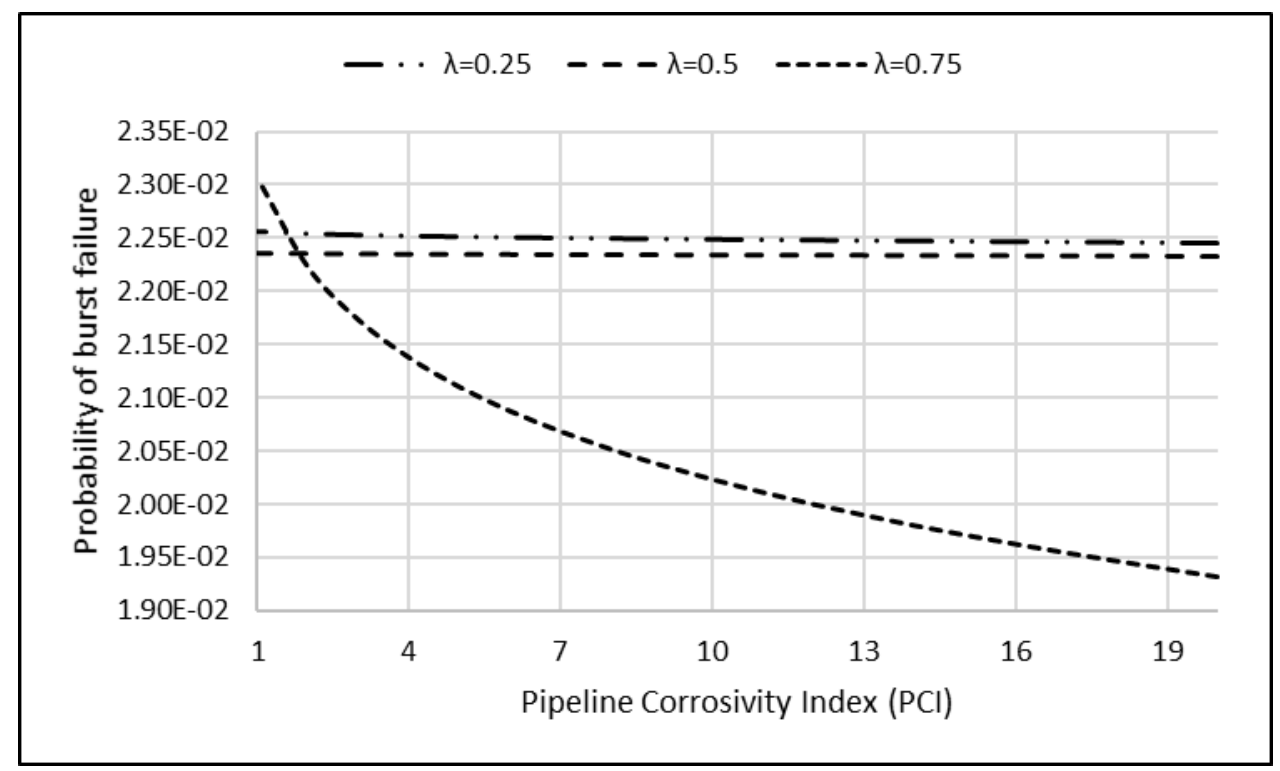

Figure 9: Failure probability resulting from burst failure at different Poisson arrival rates

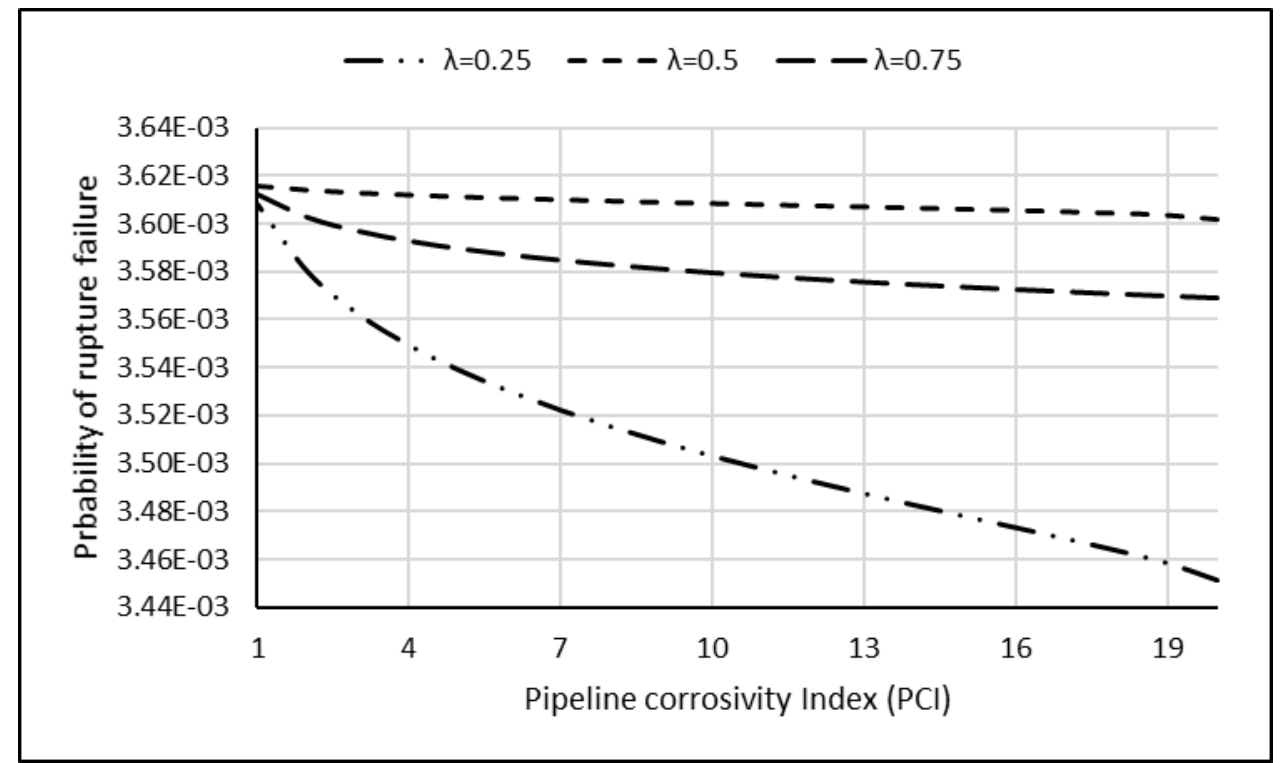

Figure 10: Failure probability of rupture failure for different Poisson arrival rates

Based on the information in Figures 8, 9 and 10 and assumption that this pipeline fails after PCI1, it can be seen that there exist between 33-41 times more chances of the pipeline having a small leakage than burst failure and approximately 203 to 257 chances of small leakage than rupture failure across the Poisson arrival intervals. There is only about 6 times more chances of failing by burst than rupture with respect to the Poisson arrival rates. This scenario holds where there is uniform corrosion wastage on the pipeline across its service life. However, due to localized corrosion and fatigue stress, it causes on the pipelines [35-36], it may be difficult to consistently expect pipeline leakage as a predominant pipeline failure mechanism as evidence abound on burst and rupture failures of corroded pipelines from localized pitting [37-1].

The reliability index of the pipeline due to small leakage, burst and rupture failures is shown in Figures 11,12 and 13 respectively. As expected, the reliability indexes decreased with the increased time of exposure of the pipelines for failure by small leakage. This is similar to the finding of other 
researchers in this area [7, 38]. For burst and rupture failures, there is only a slight change in the reliability indexes across the PCls as time of exposure of the pipeline increases. This may not be unconnected with the small failure probabilities at the PCls.

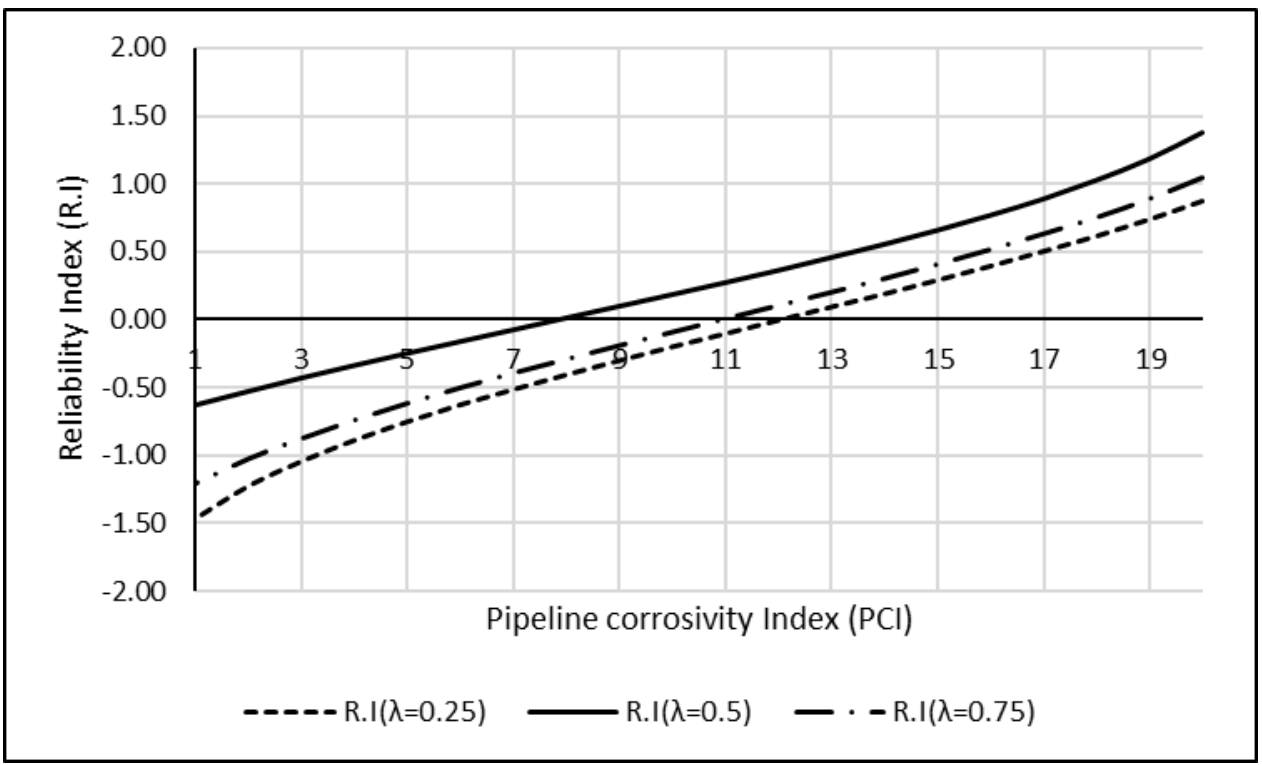

Figure 11: Reliability index for small leak at the Pipeline Corrosivity Index (PCI) for different Poisson arrival intervals

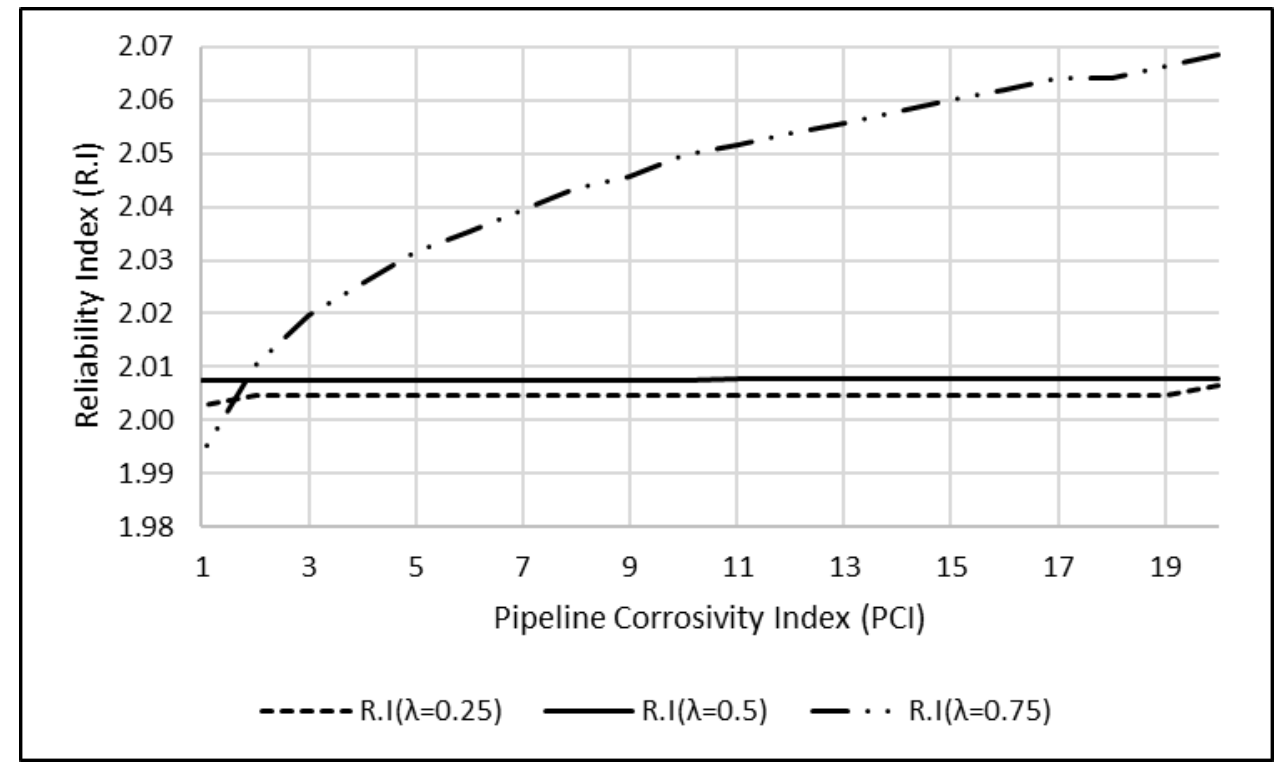

Figure 12: Reliability index for burst at the Pipeline Corrosivity Index (PCI) for different Poisson arrival intervals 


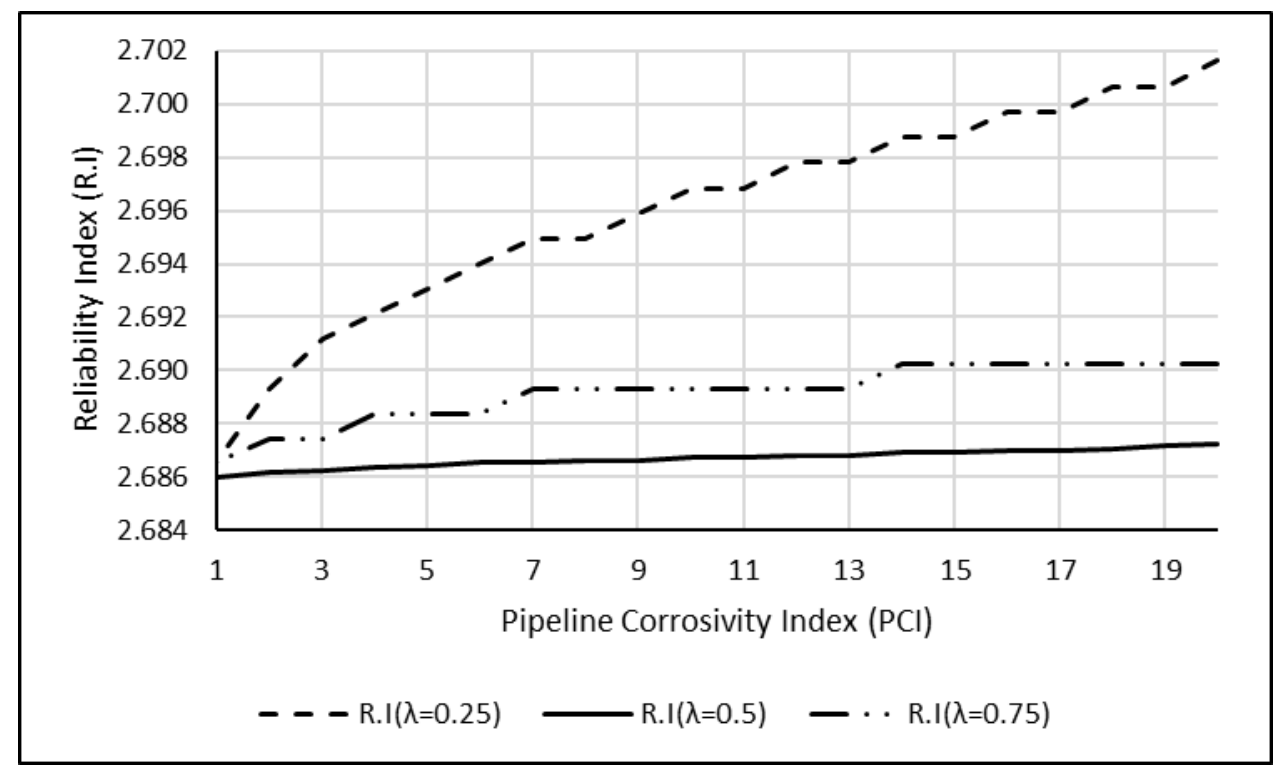

Figure 13: Reliability index for rupture at the Pipeline Corrosivity Index (PCI) for different Poisson arrival intervals

\subsection{Conclusions}

This work used Pipeline Corrosivity Index ( $\mathrm{PCl}$ ), which depended on the fraction of pipe-wall thickness retained at a given time to predict the future corrosion wastage and reliability of the pipeline. The probability of failure of internally corroded pipelines that are expected to fail by small leakage, burst and rupture were considered. The research showed that:

$>$ The failure probability of the internally corroded pipelines decreased as the time of exposure increased, with the failure probability of pipelines expected to fail by bursting slighting lower than those expected to fail by rupture.

$>$ Pipelines are more likely to fail by small leakage than bursting and rupture for an internal corroded pipeline that is devoid of other defects.

$>$ There are $33-41$ times and $203-237$ times more chances of having bursting and rupture failures respectively of an internally corroded pipeline than small leakage.

$>$ The reliability of corroded pipeline decreased with increased corrosion wastage that was necessitated by increased time of exposure of the pipeline to corrosive condition. However, there is only a slight change in the reliability of pipelines expected to fail by bursting and rupture.

It is also evident from this work that the increased rate of corrosion wastage will result in reduced time of pipeline failure due to small leakage but may not significantly impact on the burst and rupture failure of pipelines without addition defects. 


\section{Acknowledgement}

I wish to acknowledge the financial supports given to me by the Australian government, Curtin University and Western Australia Energy Research Alliance (WAERA) for my PhD research.

\section{References}

[1] Ossai, C.I., 2012, "Advances in asset management techniques: An overview of corrosion mechanisms and mitigation strategies for oil and gas pipelines," ISRN Corrosion, Article ID 570143, http://dx.doi.org/10.5402/2012/570143.

[2] Pilkey A.K., Lamberf, S. B., and Plumtree, A., 1995, "Stress Corrosion Cracking of X-60 Line Pipe Steel in a Carbonate-Bicarbonate Solution," Corrosion Science, 51(2), pp. 91-96.

[3] Fekete, G., and Varga, L., 2012, "The Effect of the Width to Length Ratios of Corrosion Defects on the Burst Pressures of Transmission Pipelines," Engineering Failure Analysis, 21, pp. 21-30.

[4] Review of corrosion management for offshore oil and gas processing, HSE offshore technology report 2001/044, Retrieved from http://www.hse.gov.uk/research/otopdf/2001/oto01044.pdf on $22 / 6 / 14$.

[5] Alberta Energy regulator (AER), Report 2013 - B: Pipeline performance in Alberta, 1990-2012, (2013), Retrieved from http://www.aer.ca/documents/reports/R2013-B.pdf 17/09/13

[6] Singh, M., and Markeset, T., 2014, "Hybrid models for handling variability and uncertainty in probabilistic and possibilistic failure analysis of corroded pipes," Engineering Failure Analysis, 42(0), pp. 197-209.

[7] Teixeira, A. P., Guedes Soares, C., Netto, T. A., and Estefen, S. F., 2008, "Reliability of pipelines with corrosion defects," International Journal of Pressure Vessels and Piping, 85(4), pp. 228237.

[8] Qian, G., Niffenegger, M., Zhou, W., and Li, S., 2013, "Effect of correlated input parameters on the failure probability of pipelines with corrosion defects by using FITNET FFS procedure," International Journal of Pressure Vessels and Piping, 105-106(0), pp. 19-27.

[9] Pandey, M. D., 1998, "Probabilistic models for condition assessment of oil and gas pipelines," NDT \& E International, 31(5), pp. 349-358.

[10] Ahammed, M., 1998, "Probabilistic estimation of remaining life of a pipeline in the presence of active corrosion defects," International Journal of Pressure Vessels and Piping, 75(4), pp. 321329. 
[11] Zhang, G., Luo, J., Zhao, X., Zhang, H., Zhang, L., and Zhang, Y., 2012, "Research on probabilistic assessment method based on the corroded pipeline assessment criteria," International Journal of Pressure Vessels and Piping, 95(0), pp. 1-6.

[12] Keshtegar, B., and Miri, M., 2014, "Reliability analysis of corroded pipes using conjugate HL-RF algorithm based on average shear stress yield criterion," Engineering Failure Analysis, 46(0), pp. 104-117.

[13] Breton, T., Sanchez-Gheno, J. C., Alamilla, J. L., and Alvarez-Ramirez, J., 2010, "Identification of failure type in corroded pipelines: A Bayesian probabilistic approach," Journal of Hazardous Materials, 179(1-3), pp. 628-634.

[14] Bisaggio, H. d. C., and Netto, T. A., 2015, "Predictive analyses of the integrity of corroded pipelines based on concepts of structural reliability and Bayesian inference," Marine Structures, 41(0), pp. 180-199.

[15] Paik, J.K. and Kim, D.K., 2012. Advanced method for the development of an empirical model to predict time-dependent corrosion wastage. Corrosion Science, 63, pp.51-58.

[16] Lee, G.H., Pouraria, H., Seo, J.K. and Paik, J.K., 2015. Burst strength behaviour of an aging subsea gas pipeline elbow in different external and internal corrosion-damaged positions. International Journal of Naval Architecture and Ocean Engineering, 7(3), pp.435-451.

[17] Review of corrosion management for offshore oil and gas processing, HSE offshore technology report 2001/044, 2001, Retrieved from http://www.hse.gov.uk/research/otopdf/2001/oto01044.pdf on 22/12/14.

[18] Ossai, C. I., 2013, "Pipeline Corrosion Prediction and Reliability Analysis: A Systematic Approach with Monte Carlo Simulation and Degradation Models," International Journal of Scientific \& Technology Research, 2(3), pp. 1-10.

[19] Nesic, S., Cai, J., Lee, K. J., 2005, “A multiphase Flow and Internal Corrosion Prediction Model for Mild Steel Pipelines", Corrosion/2005. Paper no 05556, 2005.

[20] Brazan, F. A. V. and Beck, A. T., 2013, "Stochastic process Corrosion Growth Models for Pipeline Reliability," Corrosion Science, 74, pp. 50-58.

[21] Tarantseva, K. R., 2010, "Models and Methods of Forecasting Pitting Corrosion, Protection of metals and physical chemistry of surfaces," 46(1), pp. 139-147

[22] Laycock, P. J., Cottis, R. A., and Scarf, P. A., 1990, "Extrapolation of Extreme Pit Depths in Space and Time," Journal of Electrochemical Society, 137(1), pp. 64-69

[23] Feldman, R. M. and Valdezffores, C., Applied probability and stochastic processes 2 nd edition, Springer, New York, 2010 
[24] Taylor, M. and Karlin, S., An introduction to stochastic modelling 3rd edition, Academic press San Diego, California USA, 1998,

[25] Wenxing, Z., 2010, "System reliability of corroding pipelines. International journal of pressure vessels and piping," 87, pp. 587-595.

[26] Gomes, W. J. S., Beck, A. T \& Haukaas, T., 2013, “Optimal inspection planning for onshore pipelines subject to external corrosion," Reliability Engineering and System Safety 118, pp. 1827.

[27] ASME, 1991, "Manual for determining the remaining strength of corroded pipelines," American Society of Mechanical Engineers, B31G, New York

[28] Cosham, A., Hopkins, P. \& Macdonald, K.A., 2007," Best practice for the assessment of defects in

[29] Kiefner, J.F, Maxey W.A, Eiber, R.J., Duffy, A.R., 1973, "Failure stress levels of flaws in pressurized cylinders, Progress in flaw growth and fracture toughness testing," ASTM STP 536. American Society of Testing and Materials, pp. 461e81.

[30] Ossai, C.I., Boswell, B. Davies, I. J., 2015, “Predictive Modelling of Internal Pitting Corrosion of Aged Non-Piggable Pipelines," J. Electrochem. Soc. 2015, 162(6), pp. C251-C259, doi: 10.1149/2.0701506jes

[31] Qian, G., Niffenegger, M., and Li, S., 2011, "Probabilistic analysis of pipelines with corrosion defects by using FITNET FFS procedure," Corrosion Science, 53(3), pp. 855-861.

[32] Zhang, S. and Zhou, W., 2013, "System reliability of corroding pipelines considering stochastic process-based models for defect growth and internal pressure," International Journal of Pressure Vessels and Piping 111-112, pp. 120-130

[33] Katano, Y., Miyata, K., Shimizu, H. and Isogai, T., 2003, "Predictive Model for Pit Growth on Underground Pipes," Corrosion 59(2), pp. 155-161.

[34] Cialone, H. and Holbrook, J., 1985, "Effects of gaseous hydrogen on fatigue crack growth in pipeline steel," Metallurgical and Materials Transactions A16 (1), pp. 115-122(

[35] Gajdos, L. and Sperl M., 2011, "Application of fracture mechanics approach to gas pipelines," World academy of science, engineering and technology 5, pp. 365-372

[36] Ossai, C.I., Boswell, B. Davies, I. J., 2015, "Pipeline Failures in Corrosive Environments - A Conceptual Analysis of Trends and Effects," Engineering Failure Analysis, Available online 2 April 2015, ISSN 1350-6307, http://dx.doi.org/10.1016/j.engfailanal.2015.03.004.

[37] IIman, M. N., and Kusmono, 2014, "Analysis of Internal Corrosion in Subsea Oil Pipeline," Case Studies in Engineering Failure Analysis, 2, pp. 1-8. 
[38] De Leon, D. and Macias, O. F., 2005, "Effect of spatial correlation on the failure probability of pipelines under corrosion," International Journal of Pressure Vessels and Piping 82, pp. 123-128

[39] Hernandez-Rodriguez, M. A. L., Martínez-Delgado, D., González,R. Pérez Unzueta, A., MercadoSolís, R. D., and Rodríguez, J., 2007, “Corrosive Wear Failure Analysis in a Natural Gas Pipeline," Wear, 263, pp. 567-71.

[40] Azevedo, C. R. F., 2007, "Failure Analysis of a Crude Oil Pipeline," Engineering Failure Analysis, 14, pp. 978-94.

[41] Sh Abedi, S., Abdolmaleki, A. and Adibi, N., 2007, "Failure Analysis of SCC and SRB Induced Cracking of a Transmission Oil Products Pipeline," Engineering Failure Analysis, 14, pp. 250-61 